Plant Biosystems - An International Journal Dealing with all Aspects of Plant Biology

Official Journal of the Societa Botanica Italiana

\title{
Mesocotyl elongation in Digitaria sanguinalis during seedling development
}

\section{T. Mas \& A. M. C. Verdú}

To cite this article: M. T. Mas \& A. M. C. Verdú (2016) Mesocotyl elongation in Digitaria sanguinalis during seedling development, Plant Biosystems - An International Journal Dealing with all Aspects of Plant Biology, 150:6, 1175-1181, DOI: 10.1080/11263504.2015.1009189

To link to this article: http://dx.doi.org/10.1080/11263504.2015.1009189

Accepted author version posted online: 26

Jan 2015.

Published online: 16 Feb 2015.

Submit your article to this journal $\square$

Џ Article views: 13

View related articles $₫$

View Crossmark data ¿ 


\title{
ORIGINAL ARTICLE
}

\section{Mesocotyl elongation in Digitaria sanguinalis during seedling development}

\author{
M. T. MAS \& A. M. C. VERDÚ \\ Departament d'Enginyeria Agroalimentària i Biotecnologia (DEAB), Escola Superior d'Agricultura de Barcelona (ESAB), \\ Universitat Politècnica de Catalunya (UPC), Esteve Terradas 8, 08860 Castelldefels, Barcelona, Spain
}

\begin{abstract}
The mesocotyl is an embryonic organ present in Poaceae that plays an important role in seedling emergence. The elongation of this first internode contributes decisively to the coleoptile reaching the soil surface. This study examines the process of mesocotyl elongation under controlled conditions in three caryopsis collection sites of Digitaria sanguinalis (L.) Scop. originating from Spain (Barcelona and Girona) and Argentina that may have two patterns of germination: radicular or coleoptilar. The frequencies of the two germination patterns varied significantly depending on the origin. Light inhibited the elongation of the mesocotyl drastically, resulting in maximum lengths of $3.5 \mathrm{~mm}$, while in darkness the maximum length was $57 \mathrm{~mm}$. The time-course evolution displayed under dark conditions was quite similar for all sites of origin and both germination patterns; the growth rate ranged from 0.23 to $0.30 \mathrm{~mm} \mathrm{~h}^{-1}$. Within localities, caryopses with a coleoptilar pattern of germination showed a lower growth rate than those with a radicular one.
\end{abstract}

Keywords: Germination, radicle, coleoptile, grass, host-pathogen interactions, Ustilago syntherismae

\section{Introduction}

The embryo of the representatives of the botanical family Poaceae features an axial internode located between the scutellum and the coleoptile that has been interpreted variously from a morphological point of view (Raju \& Steeves 1998) and has received several designations. In accordance with Ries and Hofmann (1991), who reviewed and standardized the terminology for morphological structures of developing grass seedlings, we will use the term mesocotyl in the present work to describe this first axial internode.

Depending on the grass species, the mesocotyl internode in the embryo can range from negligible to elongate (Watson \& Dallwitz 1992). Furthermore, regardless of the embryonic situation and again depending on the grass species, in the seedling the length of the mesocotyl can vary. For instance, both wheat and oat have an embryo with a negligible mesocotyl internode, whereas their seedlings differ considerably: in wheat the seedling mesocotyl is short but in oat it becomes a long structure.
Tucker (1957) described the ontogeny of the etiolated seedling mesocotyl of Zea mays L. and highlighted that the anatomy of the mesocotyl of this species differs greatly from that of other internodes of the shoot. As this author mentions, the mesocotyl possesses some transitional features between root and shoot. In this regard, Watanabe et al. (2006) identified Casparian bands in the rice mesocotyl.

In the genus Digitaria Haller, belonging to the subfamily Panicoideae (tribe Paniceae), the embryo possesses an elongated mesocotyl internode. Hoshikawa (1969) indicates that the subfamily Panicoideae has the type $\mathrm{E}$ underground seminal organ. This means that seedlings do not feature transitionary node roots (additional seminal roots escorting the primary root), the mesocotyl elongates and mesocotylar roots (adventitiously developed in the mesocotyl) are well developed.

Digitaria sanguinalis (L.) Scop. is known nearly worldwide as a common weed. It can show two types of germination pattern, depending on which structure emerges first and therefore is visible outside the spikelet (Verdú \& Mas 2014). In the case of the 
radicular pattern, usually considered as typical, at the base of the spikelet an emerging radicle appears, and after that the coleoptile becomes visible. For the coleoptilar type of pattern, the coleoptile is the first organ to visibly emerge between the uppermost and the lowermost chaff-like bracts of the fertile floret of the two present on the spikelet.

Moreover, seeds can resist flooding conditions in the imbibition period and can germinate successfully (Verdú \& Mas 2014). These two traits have been observed in other Poaceae such as Oryza sativa L.; Triticum aestivum L. and Echinochloa crus-galli (L.) P. Beauv.; Spartina alterniflora Loisel. and Phragmites australis (Cav.) Trin. (Kordan 1977; Bewley \& Black 1994; Wijte \& Gallagher 1996). Precisely, according to Magneschi and Perata (2009), Kordan (1974) coined the term "snorkel effect" to refer to the phenomenon of increased probability of the hollow coleoptile making contact with the better-aerated water surface.

Without any doubt, the elongation of the mesocotyl is an important trait because it is primarily responsible for the emergence of seedlings from their emplacement in the soil profile (Raju \& Steeves 1998). In this manner, the coleoptile of the seedling, which in some grasses also evidences the phenomenon of elongation, can reach the soil surface. Seedlings kept in darkness adopt a skotomorphogenic developmental plan, in which resource allocation is characteristically directed towards mesocotyl elongation.

From an agronomic point of view, the role of the mesocotyl is very important in relation to the establishment of crops and weed communities. So this feature is one of the factors taken into consideration when planning the strategy of planting, and also for weed management. For rice, mesocotyl length is one of the most important agronomic characteristics for direct seeding (Wu et al. 2005).

A healthy mesocotyl is extremely important because it transports nutrients from the endosperm of the grain to the developing seedling. The plant primarily depends on the grain's contents for its nutrients and energy until the nodal roots are developed. Therefore, seedlings may possibly be stunted or die if their nodal roots do not develop before the kernel reserves are exhausted. In like manner, if the primary leaf emerges underground it is likely that the seedling will reach the soil surface. In comparison with the coleoptile, this first leaf is less rigid and folds more easily (Andrews et al. 1997).

It is well known that seedling development patterns in light (photomorphogenesis) are distinct from those in darkness (skotomorphogenesis or etiolation) (von Arnim \& Deng 1996). Mesocotyl elongation is a response to darkness, and it ceases when the tip of the coleoptile emerges into light
(Robson et al. 1988). In rice, Hu et al. (2010, 2014) have observed that the mesocotyl is highly elongated when seedlings are grown in darkness, whereas mesocotyl elongation is dramatically inhibited under light conditions. The growth of the mesocotyl is controlled by phytohormones. Knöller et al. (2010) present a model for internode elongation in monocots, with the interaction of auxin and gibberellic acid.

Potential mesocotyl elongation tends to increase with seed size (Andrews et al. 1997). D. sanguinalis possesses caryopses with an approximate length of $3 \mathrm{~mm}$ and an average weight of $0.69 \mathrm{mg}$ (Gallart et al. 2008), and thus can be considered a small-seeded grass species. D. sanguinalis is susceptible to Ustilago syntherismae (Schwein.) Peck. With regard to the mode of fungus infection, Johnson and Baudoin (1997), working with three species of Digitaria, suggested that $U$. syntherismae is a seedling-infecting smut, a hypothesis that has been verified by Mas and Verdú (2014) in the case of $D$. sanguinalis.

We have observed mycelium of U. syntherismae in $D$. sanguinalis seedlings in the vicinity of the apical stem meristem at the base of the coleoptile, and also in the mesocotylar zone (Mas \& Verdú 2014). Knowledge of the process of mesocotyl growth in D. sanguinalis is, in the context of biological control, of great interest in relation to the route of smut infection (Johnson \& Baudoin 1997).

The present paper deals with the capacity of the mesocotyl to elongate during seed germination and early seedling development, because it is a very important stage for seedling establishment (one of the factors involved in reaching the soil surface and therefore the success of the $D$. sanguinalis weed population), and also regarding the aspect of fungus-seedling interaction (possibility of smut infection). The objectives of the present study were (i) to assess the degree of variability in the pattern of germination of seeds from different geographical origins; (ii) to determine whether there are differences in the development of the mesocotyl due to environmental signals such as light, the pattern of germination (radicular or coleoptilar) and the geographical origin of the caryopses; and (iii) to explore variability in the time course of the mesocotyl elongation

\section{Materials and methods}

\section{Plant material}

Spikelets from apparently non-diseased or healthy plants were collected by gently rubbing mature inflorescences from (i) TM, a field located near Barcelona (Torre Marimon, Caldes de Montbui, $41^{\circ} 36^{\prime} \mathrm{N}$ and $2^{\circ} 10^{\prime} \mathrm{E}$ ), in September of 2011 ; (ii) 
BES, an apple orchard located in Bescanó (Girona, $41^{\circ} 57^{\prime} \mathrm{N}$ and $2^{\circ} 43^{\prime} \mathrm{E}$ ), in October 2011 ; and (iii) ARG, a soya field located near Alberdi (Buenos Aires province, Argentina, $34^{\circ} 27^{\prime} 55^{\prime} \mathrm{S} 61^{\circ} 44^{\prime} 42.5^{\prime \prime} \mathrm{W}$ ), in April 2012. The taxonomic determination of the plants was done using Bolòs et al. (1993) and Burkart (1969). The spikelets were dry-stored at room temperature until the germination tests were carried out (February-March 2013).

\section{Germination tests}

The germination trials were performed at $20^{\circ} \mathrm{C}(12 \mathrm{~h}$ darkness $) / 30^{\circ} \mathrm{C}(12 \mathrm{~h}$ light). Before incubation, the spikelets were rinsed for $10 \mathrm{~min}$ in $5 \%$ diluted sodium hypochlorite for surface sterilization (ISTA 1985). Several lots of spikelets were placed in $9 \mathrm{~cm}$ diameter plastic Petri dishes and then transferred to the incubators. Illumination was provided by white fluorescent tubes $(4 \times 18 \mathrm{~W})$. Unless it is explicitly indicated otherwise, $3 \mathrm{ml}$ of distilled water was added to each dish at the beginning of the tests, and water was added later as required. Seeds were considered to be germinated with the emergence of the radicle or the coleoptile. Germination counts were done daily for 30 days.

\section{Seedling growth and measurement of mesocotyl length}

Once the emergence of the radical (Ra) or the coleoptilar (Co) types was observed, the spikelets of each type were transferred separately to Petri dishes (25 spikelets per dish) with $3 \mathrm{ml}$ of distilled water. The dishes were sealed with Parafilm $\odot$ to prevent moisture loss and two groups were differentiated: (i) L, under light conditions and (ii) $\mathrm{D}$, under dark conditions (the Petri dishes were in addition wrapped in aluminium foil). Several incubation periods (from 24 to $216 \mathrm{~h}$ ) were tested under the same light and temperature regime as described for the germination trials.

Mesocotyl length was measured from scutellar to coleoptilar node, using a ruler and under an optical instrument supplied with a fluorescent ring illuminator.

\section{Data analysis}

The proportions of each pattern type of germination (radicular or coleoptilar) with respect to seeds germinated were analysed using generalized linear binomial distribution models, considering the effect of geographical origin in the model. Parameters were estimated using complementary logit link function and type III analysis options. Likelihood ratio statistics were used to compute the significance of the effect. Finally, least-squares means of the levels of the effect were computed and compared using probability values from the chi-square distribution. The GENMOD procedure (SAS 2002) was used to perform both the generalized linear model and means comparisons. The experimental units were the spikelets of each Petri dish. Seven to ten Petri dishes each containing at least 200 spikelets were used for each site of origin.

The comparison of the mean mesocotyl lengths depending on the light treatment (darkness and light) did not require statistical analysis. Data on length of the mesocotyl, measured in each seedling grown under darkness conditions, were processed by means of analysis of variance using PROC MIXED (SAS 2002). The model included the fixed effects: site of origin (ARG, BES or TM), pattern of germination (radicular or coleoptilar), their interaction and time of incubation period. Petri dish was included as a random effect nested within the fixed effects. Levels of the mesocotyl growth rate least-squares mean values at $144 \mathrm{~h}$ were compared at $p<0.05$.

Regression analysis was performed to fit the timecourse evolution of mesocotyl length under dark conditions, using PROC REG (SAS 2002). The model selected was a third-degree polynomial equation without the interception term, where the dependent variable was mesocotyl length (means for each incubation period of time). Differences among the six ( 3 sites of origin $\times 2$ patterns of germination) elongation fitted curves and their parameters were tested by variance analysis using PROC GLM (SAS 2002).

\section{Results}

\section{Germination tests}

Seeds of $D$. sanguinalis from the three localities display the two different patterns of germination, radicular $(\mathrm{Ra})$ and coleoptilar $(\mathrm{Co})$, depending on the organ that first appears. For all three sites of origin, the percentages of radicular seeds were higher than those of the coleoptilar ones. The percentages of the two types observed varied depending on the seed site of origin, and the differences were statistically significant $(p<0.05)$ (Table I).

Regarding the percentage of radicular seeds obtained, the order of the seed lots from highest to lowest was Bescanó (85.5\%) > Torre Marimon $(57.6 \%)>$ Alberdi, Argentina (53.1\%).

\section{Effect of growth conditions (light and dark treatments) on seedling elongation}

The results obtained show clearly that light severely limits mesocotyl growth (Table II). With this treatment, the mesocotyl hardly elongated at all in the caryopses of any of the three localities. In the total 
Table I. Likelihood ratio statistics of the effect site of origin in the analyses of proportion of radicular type of germination, and leastsquares means of the levels of the effect obtained from data of $N$ replicates (Petri dishes) used.

\begin{tabular}{|c|c|c|c|c|c|c|c|}
\hline Effect & $\mathrm{DF}$ & $x^{2}$ & $p>\chi^{2}$ & Levels & LS mean & $\begin{array}{l}\text { Standard } \\
\text { error }\end{array}$ & $N$ \\
\hline \multirow[t]{3}{*}{$\begin{array}{l}\text { Site of } \\
\text { origin }\end{array}$} & 2 & 888.68 & $<.0001$ & ARG & $0.5489 \mathrm{~A}$ & 0.0419 & 8 \\
\hline & & & & BES & $0.8546 \mathrm{~B}$ & 0.0446 & 10 \\
\hline & & & & $\mathrm{TM}$ & $0.5839 \mathrm{C}$ & 0.0440 & 7 \\
\hline
\end{tabular}

Note: Spikelets were collected in TM, Torre Marimon (Caldes de Montbui, Barcelona, Spain); BES, Bescanó (Girona, Spain); and ARG, Alberdi (Buenos Aires, Argentina). Least-squares means with different letters are significantly different at $p<0.05$.

of seedlings measured at different intervals of time, the individual values of mesocotyl length ranged: (a) in light, from 0 to $3.5 \mathrm{~mm}$; and (b) in darkness, from 0 to $57 \mathrm{~mm}$. In Table II, we summarize the maximum and minimum mean values of mesocotyl lengths recorded in seedlings germinated under light and dark conditions. Except for the early stages $(0-36 \mathrm{~h})$, the differences between the elongation in light and darkness were great. In fact, values of $0 \mathrm{~mm}$ (in caryopses with a radicular pattern of germination) indicate inability to measure the length of the mesocotyl because the organ remained inside the bracts.

\section{Elongation of mesocotyl of dark-grown seedlings}

Except for the initial stages, time (incubation period) is the variable that explains much of the differences observed in the lengths of the mesocotyl of the 4509 seedlings measured (Table III).
Table III. Analysis of variance on the mean mesocotyl length $(\mathrm{mm})$ achieved under darkness considering the main fixed effects site of origin, pattern of germination (pattern) and time of incubation period (time) and the interaction site of origin ${ }^{\star}$ pattern.

\begin{tabular}{lccr}
\hline & $\begin{array}{c}\text { Numerator } \\
\text { Effect }\end{array}$ & & \\
\hline DF/denominator DF & $F$-value & $p>F$ \\
Site of origin & $2 / 155$ & 0.89 & 0.4129 \\
Pattern & $1 / 155$ & 2.89 & 0.0912 \\
Site of origin ${ }^{\star}$ pattern & $2 / 155$ & 3.19 & 0.0439 \\
Time & $29 / 155$ & 200.2 & $<0.0001$ \\
\hline
\end{tabular}

The length growth curves observed in seedlings developed in darkness displayed approximately the same shape (sigmoidal or S-shaped) (Figure 1). All of the models obtained, fitted using a polynomial (cubic) equation without the interception term, explain a high percentage of the data variation $\left(R^{2}\right.$ ranged from 0.977 to 0.993$)$. Generally, the pattern of seed germination (radicular or coleoptilar) does not appear to be a characteristic involving a differential degree of mesocotyl elongation under dark conditions. Two aspects are worthy of note: (1) in the initial stage of the germination, differences can be observed between radicular and coleoptilar seeds, but this is due to the fact that in the caryopses with a radicular pattern the mesocotyl remains inside the bracts and it cannot be measured; and (2) the graphs (Figure 1) where the growth in length of the mesocotyl is plotted against time show approximately S-shaped curves. In the initial stages (lag phase), the rate of mesocotyl elongation is slow, then this is followed by a rapid growth phase (log or exponential phase), and in the third or final phase

Table II. Maximum and minimum mean values of mesocotyl lengths recorded in seedlings of Digitaria sanguinalis germinated under light and dark conditions, and time (hours) at which these values were observed.

\begin{tabular}{|c|c|c|c|c|c|c|}
\hline $\begin{array}{l}\text { Site of } \\
\text { origin }\end{array}$ & PG & $\operatorname{Tr}$ & $\begin{array}{c}\text { Time of } \\
\text { minimum }(\mathrm{h})\end{array}$ & $\begin{array}{c}\text { Minimum mean } \\
\text { mesocotyl length }(\mathrm{mm})\end{array}$ & $\begin{array}{c}\text { Time of } \\
\text { maximum }(\mathrm{h})\end{array}$ & $\begin{array}{c}\text { Maximum mean } \\
\text { mesocotyl length }(\mathrm{mm})\end{array}$ \\
\hline \multirow[t]{4}{*}{ ARG } & Co & $\mathrm{L}$ & 24 & $0.241(0.039)$ & 96 & $1.129(0.042)$ \\
\hline & $\mathrm{Ra}$ & $\mathrm{L}$ & 24 & $0(0)$ & 74.3 & $0.648(0.027)$ \\
\hline & Co & $\mathrm{D}$ & 27 & $1.38(0.133)$ & 216 & $40.037(0.648)$ \\
\hline & $\mathrm{Ra}$ & $\mathrm{D}$ & 24 & $0.270(0.043)$ & 144 & $38.647(0.482)$ \\
\hline \multirow[t]{4}{*}{ BES } & Co & $\mathrm{L}$ & 24 & $0.35(0.073)$ & 96 & $1.157(0.068)$ \\
\hline & $\mathrm{Ra}$ & $\mathrm{L}$ & 24 & $0(0)$ & 96.5 & $0.84(0.047)$ \\
\hline & Co & $\mathrm{D}$ & 24 & $1.169(0.065)$ & 144 & $39.276(0.718)$ \\
\hline & $\mathrm{Ra}$ & $\mathrm{D}$ & 24 & $0.086(0.031)$ & 143 & $43.152(0.572)$ \\
\hline \multirow[t]{4}{*}{$\mathrm{TM}$} & Co & $\mathrm{L}$ & 24 & $0.505(0.027)$ & 120 & $1.204(0.035)$ \\
\hline & $\mathrm{Ra}$ & $\mathrm{L}$ & 24 & $0(0)$ & 143.5 & $0.6(0.024)$ \\
\hline & Co & $\mathrm{D}$ & 24 & $1.865(0.066)$ & 144 & $36.464(1.066)$ \\
\hline & $\mathrm{Ra}$ & $\mathrm{D}$ & 24 & $0.312(0.044)$ & 185 & $44.236(0.540)$ \\
\hline
\end{tabular}

Note: Caryopses were collected in TM, Torre Marimon (Caldes de Montbui, Barcelona, Spain); BES, Bescanó (Girona, Spain); and ARG, Alberdi (Buenos Aires, Argentina). The values in parentheses are standard errors of the mean. Treatment (Tr): L, light; D, darkness. Pattern of germination (PG): Co, coleoptilar; Ra, radicular. 

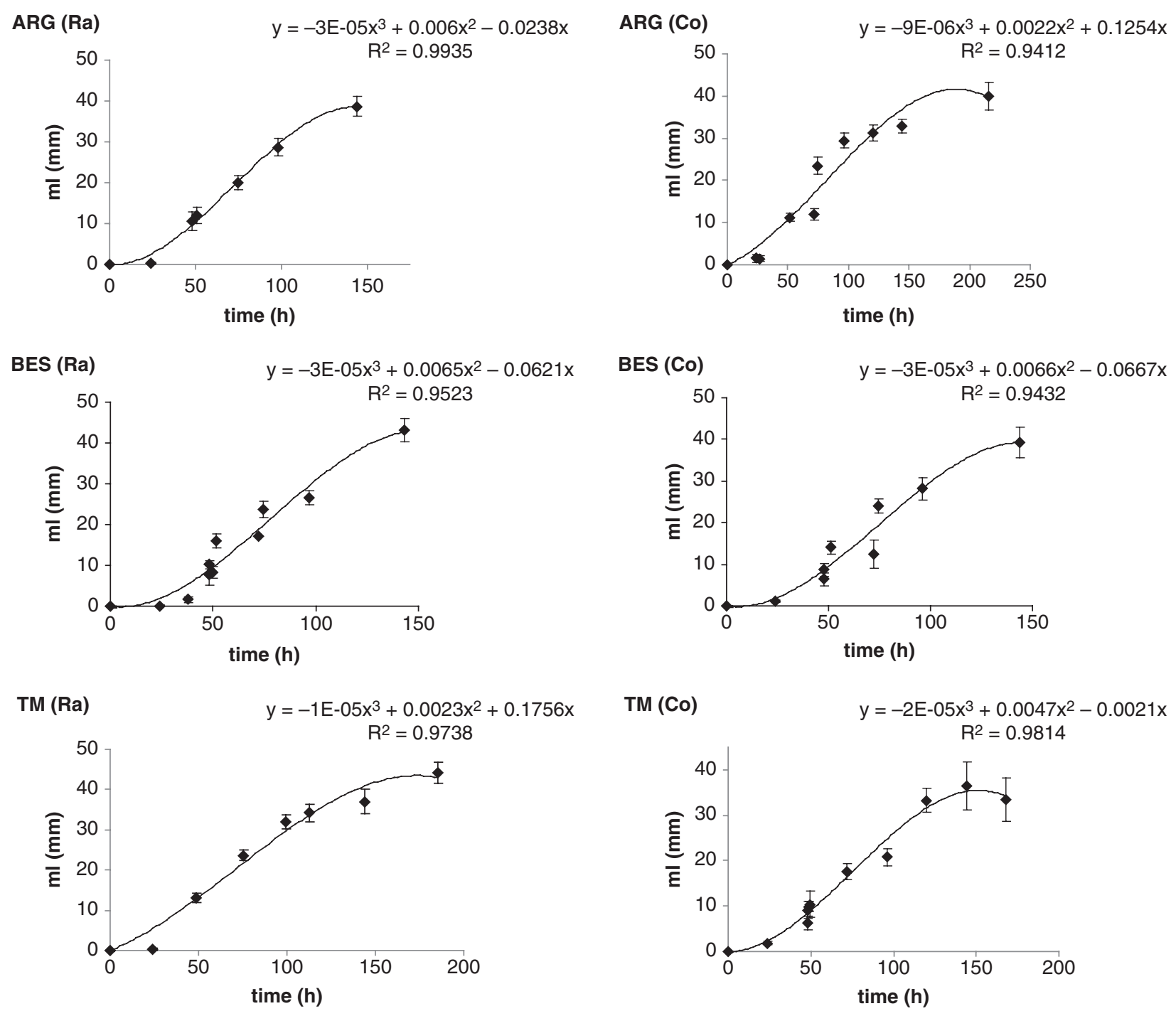

Figure 1. Time course of mesocotyl elongation (ml, mean mesocotyl length) of dark-grown Digitaria sanguinalis seedlings. Caryopses were collected in TM, Torre Marimon (Caldes de Montbui, Barcelona, Spain); BES, Bescanó (Girona, Spain); and ARG, Alberdi (Buenos Aires, Argentina). The values of the standard error bars are multiplied by 5 .

(stationary phase), when it is possible to observe it (TM-Co and ARG-Co) the elongation slows down. Two-by-two comparison of the curves showed significant differences only between the evolution of TM-Co and $\mathrm{Ra}$, mainly due to the differences in the final stage.

Table IV displays the growth rate $144 \mathrm{~h}$ after seed germination ( $143 \mathrm{~h}$ in BES-Ra) measured in 699 seedlings. For all three seed sites of origin, the values of $\mathrm{Ra}$ are higher than those of $\mathrm{Co}$, but differences were significant $(p<0.05)$ only for the Argentinean locality. The comparison of the mean mesocotyl length within each seed site of origin shows significant differences $(p<0.05)$ between: (i) BES-Ra and ARG-Ra, BES-Ra and TM-Ra; (ii) ARG-Co and BES-Co. The maximum value was observed in BES-Ra seedlings, and the minimum in ARG-Co.

\section{Discussion}

The two patterns of germination found in caryopses from Torre Marimon (Verdú \& Mas 2014) were also observed in caryopses from Bescanó and Alberdi (Argentina). Furthermore, this trait showed variability among the localities, so the frequencies of each type detected for each location were different (Table I). This is a very interesting characteristic to explore how the frequency of the germination pattern can be affected by habitat traits, in particular crop management (soil tillage in orchard vs. cereal crop, irrigated vs. non-irrigated land, etc.).

As $\mathrm{Hu}$ et al. (2010) point out, the elongation of the mesocotyl is controlled by multiple genetic, developmental and environmental signals. The inhibition of mesocotyl growth by light is a general feature in plants, recognized since 1894 (Vanderhoef 
Table IV. Least-squares means comparison of the mean mesocotyl growth rate $\left(\mathrm{mm} \mathrm{h}^{-1}\right)$ achieved under $144 \mathrm{~h}$ dark treatment, performed considering the main effects site of origin and pattern of germination and their interaction.

\begin{tabular}{lll}
\hline \multirow{2}{*}{ Site of origin } & \multicolumn{2}{c}{ Pattern of germination } \\
\cline { 2 - 3 } & Radicular & Coleoptilar \\
\hline ARG & $0.266^{\star} \mathrm{A}$ & $0.229^{\star} \mathrm{A}$ \\
$\mathrm{BES}$ & $0.300 \mathrm{~B}$ & $0.273 \mathrm{~B}$ \\
$\mathrm{TM}$ & $0.257 \mathrm{~A}$ & $0.253 \mathrm{AB}$ \\
\hline
\end{tabular}

Note: Spikelets were collected in TM, Torre Marimon (Caldes de Montbui, Barcelona, Spain); BES, Bescanó (Girona, Spain); and ARG, Alberdi (Buenos Aires, Argentina). In rows, least-squares means marked with * are significantly different. In columns, leastsquares means with different letters are significantly different $(p<0.05)$.

et al. 1979). In line with this, our results show that, in D. sanguinalis, mesocotyl elongation in light was extremely limited, the maximum length recorded being $3.5 \mathrm{~mm}$. The mechanism of light-induced growth inhibition is not yet fully understood and may include light-induced changes in hormone homeostasis (Fellner et al. 2006). In a work on screening for rice germplasms with specially elongated mesocotyl, Wu et al. (2005) confirmed that under daylight conditions, the mesocotyl did not elongate in 96 varieties. The authors pointed out that this may be due to the suppression of the genes which mediate in the elongation of the mesocotyl and the decomposition or passivation of enzymes under daylight conditions.

Although in the present work we have not been able to verify how the mesocotyl develops during its elongation, several situations appear in the literature. In the case of rice, $\mathrm{Hu}$ et al. (2010) indicates that mesocotyl growth is controlled by both an increase in the number of cells (meristematic activity) and the lengthwise elongation of each cell. However, in Echinochloa, depending on the species, in addition to cell elongation there may or may not be cell division (VanderZee \& Kennedy 1981; Yasue \& Kawase 1976).

Mesocotyl elongation is an important trait for seedling emergence. Raju and Steeves (1998) indicate that the success of weeds can be attributed to several factors, and one of them is the ability of seedlings to reach the soil surface. The maximum length of the mesocotyl observed in the present work (57 mm, Table II) confirms the results obtained by Benvenuti et al. (2001), who studied the effects of seed burial depth on the ability of seedling emergence, and they found that beyond $6 \mathrm{~cm}$ there was no emergence.

In $D$. sanguinalis, among the three sites of origin of the caryopses tested, we observed low variability in the ability of mesocotyl growth in darkness. For example, the growth rate $\left(\mathrm{mm} \mathrm{h}^{-1}\right) 144 \mathrm{~h}$ after seed germination ranged from 0.23 to 0.30 . The final length of the mesocotyl after the elongation process in darkness does not seem to vary much due to the collection site of the caryopses and the pattern of germination (Table III, Figure 1). It is necessary to study this aspect in greater depth if we consider the pathosystem Digitaria sanguinalis-Ustilago syntherismae. The infective hyphae of the fungus may enter the seedling through the stomata of the coleoptile or may penetrate the mesocotylar area (Mas \& Verdú 2014). From this perspective, knowledge of the process of mesocotyl elongation under dark conditions becomes important, since in the field in spring spores and seeds start to germinate in the soil.

\section{Acknowledgements}

We gratefully appreciate the technical assistance of M. Julià and Sheila Alcalá. We also thank the Institut de Recerca i Tecnologia Agroalimentàries (IRTA) for providing field space, and J. Girbal for his collaboration in collecting spikelets in Bescanó (Girona, Spain).

\section{Funding}

This work was financially supported in part by Fondo para la Investigación Científica y Tecnológica (FONCYT) - Argentina (Proyectos de Investigación Científica y Tecnológica - PICT 2010-2055).

\section{References}

Andrews M, Andrews ME, Watson C, Percival SM. 1997. Emergence of small and large seeded grasses: Importance of shoot strength. Session 22 - Forage and Grassland Management. Proceedings XVIII IGC 1997 Winnipeg, Manitoba. pp. 27-28.

Benvenuti S, Macchia M, Miele S. 2001. Quantitative analysis of emergence of seedlings from buried weed seeds with increasing soil depth. Weed Sci 49(4): 528-535. doi:10.1614/0043-1745 (2001)049[0528:QAOEOS]2.0.CO;2.

Bewley JD, Black M. 1994. Seeds: Physiology of development and germination. New York: Plenum Press.

Bolòs O de, Vigo J, Masalles RM, Ninot JM. 1993. Flora manual dels Països Catalans. Barcelona: Pòrtic.

Burkart A. 1969. Flora Ilustrada de Entre Ríos. Parte II Gramínias. Colección Científica del INTA, Buenos Aires, Argentina.

Fellner M, Ford ED, Van Volkerburgh E. 2006. Development of erect leaves in a modern maize hybrid is associated with reduced responsiveness to auxin and light of young seedlings in vitro. Plant Signal Behav 1(4): 201-211. doi:10.4161/psb.1. 4.3106.

Gallart M, Verdú AMC, Mas MT. 2008. Dormancy breaking in Digitaria sanguinalis seeds: The role of the caryopsis covering structures. Seed Sci Technol 36(2): 259-270. doi:10.15258/ sst.2008.36.2.01.

Hoshikawa K. 1969. Underground organs of the seedlings and the systematics of Gramineae. Bot Gaz 130(3): 192-203. doi:10. $1086 / 336490$. 
Hu Z, Yamauchi T, Yang J, Jikumaru J, Tsuchida-Mayama T, Ichikawa H, et al. 2014. Strigolactone and cytokinin act antagonistically in regulating rice mesocotyl elongation in darkness. Plant Cell Physiol 55(1): 30-41. doi:10.1093/pcp/ pct150.

Hu Z, Yan H, Yang J, Yamaguchi S, Maekawa M, Takamure I, et al. 2010. Strigolactones negatively regulate mesocotyl elongation in rice during germination and growth in darkness. Plant Cell Physiol 51(7): 1136-1142. doi:10.1093/pcp/ pcq075.

International Seed Testing Association 1985. International rules for seed testing: Rules and annexes. Seed Sci Technol 13: $299-515$.

Johnson DA, Baudoin ABAM. 1997. Mode of infection and factors affecting disease incidence of loose smut of crabgrass. Biol Control 10(2): 92-97. doi:10.1006/bcon.1997.0555.

Knöller AS, Blakeslee JJ, Richards EL, Peer WA, Murphy AS. 2010. Brachytic2/ZmABCB1 functions in IAA export from intercalary meristems. J Exp Bot 61: 3689-3696.

Kordan HA. 1974. Patterns of shoot and root growth in rice seedlings germinating under water. J Appl Ecol 11(2): 685-690. doi:10.2307/2402218.

Kordan HA. 1977. Coleoptile emergence in rice seedlings in different oxygen environments. Ann Bot-London 41: 1205-1209.

Magneschi L, Perata P. 2009. Rice germination and seedling growth in the absence of oxygen. Ann Bot-London 103(2): 181-196. doi:10.1093/aob/mcn 121 .

Mas MT, Verdú AMC. 2014. Within-population variation in resistance of Digitaria sanguinalis to Ustilago syntherismae resulting from different modes of seed germination and environment. Plant Pathol 63(1): 140-147. doi:10.1111/ppa. 12084.

Raju MVS, Steeves TA. 1998. Growth, anatomy and morphology of the mesocotyl and the growth of appendages of the wild oat (Avena fatua L.) seedling. J Plant Res 111(1): 73-85. doi:10. 1007/BF02507152.

Ries RE, Hofmann L. 1991. Research observations: Standardized terminology for structures resulting in emergence and crown placement of 3 perennial grasses. J Range Manage 44(4): 404-407. doi:10.2307/4002409.

Robson MJ, Ryle GJA, Woledge J. 1988. The grass plant - Its form and function. In: Jones MB, Lazenby A, editors. The grass crop. London: Chapman \& Hall. pp. 25-83.
SAS. 2002. Statistical analysis systems, Software Version 9.2. Cary, NC: SAS Institute, Inc.

Tucker SC. 1957. Ontogeny of the etiolated seedling mesocotyl of Zea mays. Bot Gaz 118(3): 160-174. doi:10.1086/335940.

Vanderhoef LN, Quail PH, Briggs WR. 1979. Red light-inhibited mesocotyl elongation in maize seedlings: II. Kinetic and spectral studies. Plant Physiol 63(6): 1062-1067. doi:10.1104/ pp.63.6.1062.

VanderZee D, Kennedy RA. 1981. Germination and seedling growth in Echinochloa crus-galli var. oryzicola under anoxic conditions: Structural aspects. Am J Bot 68(9): 1269-1277. doi: $10.2307 / 2443051$

Verdú AMC, Mas MT. 2014. Digitaria sanguinalis seedling development pattern: Relationship with seed origin. Plant Biosyst 148: 42-48.

von Arnim A, Deng X. 1996. Light control of seedling development. Annu Rev Plant Phys 47(1): 215-243. doi:10. 1146/annurev.arplant.47.1.215.

Watanabe H, Saigusa M, Morita S. 2006. Identification of casparian bands in the mesocotyl and lower internodes of rice (Oryza sativa L.) seedlings using fluorescence microscopy. Plant Prod Sci 9(4): 390-394. doi:10.1626/pps.9.390.

Watson L, Dallwitz MJ. 1992 onwards. The grass genera of the world: Descriptions, illustrations, identification, and information retrieval; including synonyms, morphology, anatomy, physiology, phytochemistry, cytology, classification, pathogens, world and local distribution, and references. Version: 5 February 2014. [online]. Available: http://delta-intkey.com. Accessed Mar 201412.

Wijte A, Gallagher JL. 1996. Effect of oxygen availability and salinity on early life history stages of salt marsh plants. I. Different germination strategies of Spartina alterniflora and Phragmites australis (Poaceae). Am J Bot 83(10): 1337-1342. doi:10.2307/2446119.

Wu M, Zhang G, Lin J, Cheng S. 2005. Screening for rice germplasms with specially-elongated mesocotyl. Rice Sci 12: $226-228$.

Yasue T, Kawase Y. 1976. Studies on the japanese barnyard millet as soiling crop: III. Mesocotyl elongation in Japanese barnyard millet seedling. Jpn J Crop Sci 45(1): 91-98. doi:10.1626/jcs. 45.91 . 